\title{
Growth in Very Preterm Children: A Longitudinal Study
}

\author{
AIMON NIKLASSON, EVA ENGSTRÖM, ANNA-LENA HÅRD, \\ KERSTIN ALBERTSSON WIKLAND, AND ANN HELLSTRÖM \\ Göteborg Pediatric Growth Research Center, Department of Pediatrics, Institute of The Health of Women \\ and Children, Department of Ophthalmology, Institute of Clinical Neuroscience's, The Sahlgrenska \\ Academy at Göteborg University, The Queen Silvia Children's Hospital, 41685 Göteborg, Sweden
} \begin{abstract}
ABS
The knowledge about the long-term growth of very preterm
children in relation to gestational age at birth is incomplete. Therefore, a retrospective study of longitudinal growth from birth to $7 \mathrm{y}$ of age in 52 of 56 surviving children who were born at a gestational age of $<29$ wk between 1988 and 1991 to mothers resident in the city of Göteborg, Sweden, was performed. A majority of the children had an initial decrease in weight during the first months of life, followed by an increase, with a maximum weight gain occurring at 36-40 wk postmenstrual age. After a period of decreased weight and length velocity, a second increase in weight velocity was demonstrated from 6 mo to $2 \mathrm{y}$ of corrected age. A corresponding increase in length velocity was found from 2 to 12 mo of corrected age. A later catch-up growth period was found at $4-5 \mathrm{y}$ of age. At $7 \mathrm{y}$ of age,
\end{abstract}

all but two had reached the normal height range of the population. This long-term catch-up in height was established later in those who were born at an earlier gestational age. We conclude that all preterm infants had an initial period of poor growth, which rendered them growth retarded during the first years of life. It took approximately $4-7 \mathrm{y}$ to overcome what the very preterm child lost in growth during the first months of life. However, as a group, they did reach normal height, weight, and weight for height before puberty. (Pediatr Res 54: 899-905, 2003)

\section{GA, gestational age}

\section{Abbreviations}

SDS, SD score
The past decades have seen an ongoing improvement in perinatal and neonatal intensive care that has resulted in an increasing number of infants' surviving after being born very immature. In the literature, this group is often referred to as very low birth weight infants, i.e. a birth weight of $1500 \mathrm{~g}$ or less. It is important to understand that very low birth weight infants represent a heterogeneous group of newborns that includes preterm infants who have a weight that is normal for gestational age (GA) but also more mature growth-retarded infants (1). Ongoing changes in the treatment of these infants have made this population a difficult group for follow-up studies. So far, there are only a few follow-up studies of longitudinal growth until school age in children with a low birth weight in relation to GA. However, a follow-up study of children with a low birth weight independent of GA, up to the

Received January 22, 2001; accepted January 142003.

Correspondence: Aimon Niklasson MD, PhD, Göteborg Pediatric Growth Research Centre, Department of Pediatrics, The Queen Silvia Children's Hospital, S-416 85 Göteborg, Sweden; email: aimon.niklasson@vgregion.se

This work was supported by grants from The Swedish Medical Research Council (7509, 10863, and 13515), The Knut and Alice Wallenberg Foundation, The FrimurareBarnhusdirektionen, The Göteborg Medical Society, and Vilhelm och Martina Lundgrens Foundation.

DOI: 10.1203/01.PDR.0000091287.38691.EF age of $8 \mathrm{y}$, demonstrated that these children had a subnormal weight as well as subnormal height development compared with children of normal birth weight at a comparable age. In addition, they needed a longer time for catch-up growth (2). In that study, no account was taken of differences in GA.

During the past decade, several studies have pointed out the relationship among low birth weight, postnatal growth, and morbidity and mortality as a result of cardiovascular disease (3-5), as well as disturbances in cognitive function in later life (6). Hence, it seems to be important to study the long-term growth of infants who are born very immature to define the growth of children who have had an early interruption of their intrauterine life. Therefore, we conducted a study with the aim to characterize longitudinal growth in a population-based group of preterm children who were born at a GA of $<29$ wk.

\section{METHODS}

Characteristics and selection of study group. All surviving children $(n=56)$ who were born at a GA of $<29$ wk between 1988 and 1991 to mothers resident in the city of Göteborg were invited to participate in a retrospective study of longitudinal growth at the Göteborg Pediatric Growth Research Center, The Queen Silvia Children's Hospital. Two children could not be 
contacted, and two did not agree to participate. Thus, 52 children were included in the study (31 boys and 21 girls) with a GA ranging from $24+0$ to $28+6 \mathrm{wk}$. The number of children and their weight at each GA are presented in Table 1. The children were followed to at least the age of $7 \mathrm{y}$, except for one girl, who was followed until 3 y of age. Three of the 52 children (two girls and one boy) who were on GH treatment at the time of the study were included only until the start of therapy ( $2 \mathrm{y}$ and $10 \mathrm{mo}, 3 \mathrm{y}$ and $8 \mathrm{mo}$, and $4 \mathrm{y}$ and $10 \mathrm{mo}$ of corrected age).

The group included four pairs of twins. All infants were without any obvious chromosomal aberrations or other major malformations. Thirty (53.6\%) of the infants where delivered by cesarean section. The morbidity variables for the included children are presented in Table 2. Fifty-one of the children in this study were previously included in an ophthalmologic study of visual function in very preterm children (7).

Data collection. The time of the mother's last menstrual period was recorded, and GA was estimated by fetal ultrasonography, performed at week 17 of gestation. The fetal ultrasonographic data were used to determine the GA at birth in all cases except one, in whom an ultrasonographic examination was not performed.

Data regarding GA, weight, and length at birth and growth measurements later in life were collected from hospital files, child health care units, and schools. The ages at the time of measurement were corrected for GA. Corrected age therefore means the age the child would have had if born at $40 \mathrm{wk}$ of GA. In the majority of infants, measurements were performed monthly from discharge to 6 mo of corrected age and thereafter at 10,12 , and $18 \mathrm{mo}$ of age and then yearly. Parents were asked to report their current height.

Measuring technique. Trained nurses at the neonatal intensive care unit measured weight at birth. Thereafter, weight was measured and recorded repeatedly until discharge from hospital, which, in most cases, coincided with an age corresponding to 40 wk postmenstrual age. Length was not regularly measured (because of clinical practice) before the child was close to being discharged. After the hospital period, skilled personnel measured both weight and length during health checks either at the hospital or at child health care units. From 6 to $7 \mathrm{y}$ of age, trained school nurses took the measurements. Height was measured as supine length on a measuring board until the child could stand unaided at approximately 2 y of age, when measurements were made using a stadiometer attached to the wall.

Growth data. Reference data based on estimated fetal weight were used (8). These values are in agreement with reference data currently being developed based on Swedish infants born preterm (9).

From 40 wk of gestation to $7 \mathrm{y}$ of age, the official Swedish growth chart has been used (10). The midparental heights of the children included in the reference material have been used for comparison in the present study (11).

For determining weight and length/height at predefined exact corrected ages, four-degree polynomial curves were fitted for each child and variable. Interpolated values were then calculated for the predefined ages. SD scores (SDS) were calculated using the references. The SDS is determined as (mean-actual value)/SD. Midparental height was calculated as the mean of both parents, SDS. $\triangle$ SDS was then calculated for each infant as the change in SDS for the predefined periods.

Statistical analysis. The SAS (6.12) package for a personal computer was used for calculation of polynomial models, means, regression lines with $95 \%$ confidence limits, and linear multiple regression.

Ethical approval. The Ethical Committee at the Medical Faculty, Göteborg University, approved the study. Written informed consent was obtained from the parents.

\section{RESULTS}

Weight from birth to 40 gestational wk. No differences were found as a result of sex, and there was no correlation between weight SDS at birth and parental size.

The most immature infants (GA 24-25 wk), according to the reference material, all were born within the normal weight range. Among the children who were born with a GA above 26 wk, three children were born small for gestational age, i.e. $<-2$ SDS in weight.

After birth, a majority of the 52 infants demonstrated a typical sinusoidal curve regarding change in weight SDS to 40 wk postmenstrual age (Table 3). Initially, an immediate marked drop was demonstrated during the first month of life, with a tendency for the greatest loss among the most immature infants. After a transition period, a significant and continuous catch-up growth was seen until $40 \mathrm{wk}$ postmenstrual age. Infants who were born at $28 \mathrm{wk}$ of gestation had a normal weight at $40 \mathrm{wk}$ corrected age (mean $\operatorname{SDS}=0.25$ ) in contrast to infants who were born before $27 \mathrm{wk}$ of gestation (Table 4). Table 5 shows the individual SDS changes during predefined periods (no difference between different Gas; data not shown). In a majority of the children (41 of 52), the negative values

Table 1. Number of patients born in each gestational week together with the total number of live-born infants in the same gestational weeks, to mothers resident in the city of Göteborg at delivery, during the time period 1988-1991

\begin{tabular}{lcccc}
\hline GA (wk) & Total $n$ & Surviving & Participating & Mean weight (g; max-min) \\
\hline$(22-23)$ & $(7)$ & 0 & 0 & - \\
24 & 8 & 4 & 4 & $663(550-755)$ \\
25 & 9 & 5 & 5 & $678(650-880)$ \\
26 & 13 & 7 & 7 & $785(450-1000)$ \\
27 & 21 & 11 & 11 & $1015(570-1355)$ \\
28 & 32 & 29 & 25 & $1180(690-1520)$ \\
Total sum & $90(97)$ & 56 & 52 & - \\
\hline
\end{tabular}


Table 2. Morbidity in each gestational week

\begin{tabular}{|c|c|c|c|c|c|}
\hline \multirow[b]{2}{*}{ Morbidity variable } & \multicolumn{5}{|c|}{ Gestational age (wk) } \\
\hline & $24(n=4)$ & $25(n=5)$ & $26(n=7)$ & $27(n=11)$ & $28(n=25)$ \\
\hline ROP (median) & 3 & 3 & 2 & 0 & 0 \\
\hline Oxygen treatment (d; median) & 118 & 123 & 50 & 42 & 27 \\
\hline Assisted ventilation (d; median) & 29 & 90 & 0 & 0 & 0 \\
\hline Oxygen treatment $>40 \%(\mathrm{~d} ;$ median $)$ & 34 & 31 & 13 & 4 & 3 \\
\hline Abnormal neuroimaging* $(n)$ & 1 & 1 & 3 & 2 & 6 \\
\hline C-reactive protein $>50 \mathrm{mg} / \mathrm{L}(n)$ & 2 & 2 & 1 & 1 & 2 \\
\hline $\operatorname{BPD}(n)$ & 2 & 1 & 0 & 0 & 1 \\
\hline
\end{tabular}

Intracranial hemorrhage was diagnosed by perinatal ultrasonography and graded 1-4 according to Papile et al. (30).

ROP, retinopathy of prematurity; BPD, bronchopulmonary dysplasia.

BPD was defined as oxygen supply at 36 gestational wk in addition to classical radiologic BPD findings. Occurrence of ROP was graded $1-5$ according to the classification of ROP (31). Medians are given as bold figures.

* Ultrasound.

Table 3. Weight SDS for 52 infants born before 29 wk GA

\begin{tabular}{|c|c|c|c|c|c|}
\hline Corrected age $(n)$ & Lower $95 \%$ & Mean & Upper $95 \%$ & Min & Max \\
\hline 28 wk (52) & -1.72 & -1.35 & -0.99 & -4.07 & 1.08 \\
\hline 32 wk (52) & -1.46 & -1.17 & -0.88 & -3.07 & 1.15 \\
\hline 36 wk (52) & -1.46 & -1.17 & -0.87 & -3.23 & 1.20 \\
\hline $1 \mathrm{mo}(52)$ & -0.64 & -0.32 & 0.00 & -3.57 & 2.12 \\
\hline 2 mo (52) & -1.11 & -0.75 & -0.39 & -4.59 & 1.96 \\
\hline 3 mo (52) & -1.53 & -1.13 & -0.74 & -5.57 & 1.76 \\
\hline 2 y $(52)$ & -1.21 & -0.78 & -0.37 & -5.04 & 1.91 \\
\hline 3 y $(52)$ & -1.29 & -0.88 & -0.47 & -4.39 & 2.71 \\
\hline 4 y (49) & -1.15 & -0.76 & -0.36 & -3.84 & 3.47 \\
\hline 5 y (48) & -0.76 & -0.38 & 0.00 & -3.53 & 4.00 \\
\hline 6 y (48) & -0.41 & -0.04 & 0.33 & -2.55 & 4.08 \\
\hline 7 y (48) & -0.40 & -0.02 & 0.37 & -2.67 & 3.38 \\
\hline
\end{tabular}

Mean, upper, and lower $95 \%$ confidence interval of the mean and min, max are given. Mean and upper confidence limits of the mean below reference $=0$ are indicated in bold.

Table 4. Weight SDS for infants born at 28 wk GA and comparison with lower GAs

\begin{tabular}{|c|c|c|c|c|c|c|}
\hline $\begin{array}{l}\text { Corrected } \\
\text { age }\end{array}$ & $\begin{array}{c}\text { Lower } 95 \% \\
28 \mathrm{wk}\end{array}$ & $\begin{array}{c}\text { Mean } \\
28 \mathrm{wk} \\
(n=25)\end{array}$ & $\begin{array}{c}\text { Upper } 95 \% \\
28 \mathrm{wk}\end{array}$ & $\begin{array}{c}\text { Upper } 95 \% \\
<28 \text { wk } \\
(n=27-23)\end{array}$ & $\begin{array}{l}\text { Upper } 95 \% \\
<27 \text { wk } \\
(n=16-13)\end{array}$ & $\begin{array}{c}\text { Upper } 95 \% \\
<26 \text { wk } \\
(n=9-7)\end{array}$ \\
\hline $28 \mathrm{wk}$ & -1.98 & -1.41 & -0.87 & -0.80 & -0.77 & -0.32 \\
\hline 32 wk & -1.33 & -0.91 & -0.51 & -1.01 & -1.07 & -0.74 \\
\hline $36 \mathrm{wk}$ & -1.22 & -0.81 & -0.42 & -1.11 & -1.28 & -1.15 \\
\hline $40 \mathrm{wk}$ & -0.15 & 0.25 & 0.63 & -0.10 & -0.33 & -0.28 \\
\hline $1 \mathrm{mo}$ & -0.39 & -0.03 & 0.33 & -0.07 & -0.26 & -0.15 \\
\hline $2 \mathrm{mo}$ & -0.82 & -0.44 & -0.06 & -0.45 & -0.68 & -0.52 \\
\hline $3 \mathrm{mo}$ & -1.23 & -0.81 & -0.40 & -0.78 & -1.03 & -0.84 \\
\hline $6 \mathrm{mo}$ & -1.86 & -1.39 & -0.92 & -1.28 & -1.54 & -1.28 \\
\hline $1 \mathrm{y}$ & -1.28 & -0.83 & -0.38 & -0.72 & -0.91 & -0.54 \\
\hline $2 y$ & -0.93 & -0.50 & -0.07 & -0.35 & -0.39 & 0.11 \\
\hline $3 y$ & -1.10 & -0.64 & -0.20 & -0.42 & -0.45 & 0.17 \\
\hline $4 y$ & -1.07 & -0.63 & -0.19 & -0.21 & -0.41 & 0.35 \\
\hline $5 y$ & -0.76 & -0.33 & 0.10 & 0.22 & -0.01 & 0.61 \\
\hline $6 y$ & -0.45 & -0.02 & 0.41 & 0.58 & 0.43 & 1.06 \\
\hline $7 y$ & -0.48 & -0.03 & 0.41 & 0.66 & 0.75 & 1.45 \\
\hline
\end{tabular}

Mean and upper confidence limits of the mean below reference $=0$ are indicated in bold. Separate $95 \%$ confidence intervals for the means (comparison with 28 wk of gestation) are indicated by italics. Decreasing number $(n)$ as a result of excluded GH-treated children.

from the 32- to 36-wk period were followed by a catch-up growth until estimated normal term (i.e. 40 wk postmenstrual age)

Weight from 40 wk of gestation to 7 y of age. After $40 \mathrm{wk}$ (postmenstrual age), mean weight SDS decreased to approximately -1.7 SDS for the total group and to approximately
-1.4 SDS for the 28 wk subgroup (Tables 3 and 4). The individual changes in SDS $(\Delta \mathrm{SDS})$ were negative until 6 mo of corrected age (Table 5). Between 6 mo and 2 y of age, $\Delta$ SDS indicated catch-up growth. This catch-up growth was also seen during the age period of 4-6 y. In the period between 2-4 y and 6-7 y, no such shift in SDS was found. 
Table 5. Mean $\triangle S D S$ for weight (individual changes) in all children for each time period

\begin{tabular}{|c|c|c|c|c|c|c|}
\hline Period & $\begin{array}{l}\text { Mean age } \\
(\mathrm{yr})\end{array}$ & $n$ & $\begin{array}{c}\text { Mean } \Delta \text { SDS } \\
\text { weight }\end{array}$ & SD & $\begin{array}{l}\text { Lower } \\
95 \%\end{array}$ & $\begin{array}{l}\text { Upper } \\
95 \%\end{array}$ \\
\hline $28-32$ wk & -0.21 & 52 & 0.21 & 1.55 & -0.23 & 0.64 \\
\hline $32-36 \mathrm{wk}$ & -0.13 & 52 & -0.37 & 0.64 & -0.55 & -0.19 \\
\hline 0-1 mo & 0.042 & 52 & -0.40 & 0.25 & -0.47 & -0.33 \\
\hline 1-2 mo & 0.130 & 52 & -0.43 & 0.23 & -0.49 & -0.37 \\
\hline 2-3 mo & 0.21 & 52 & -0.39 & 0.20 & -0.44 & -0.33 \\
\hline $1-2 y$ & 1.50 & 52 & 0.40 & 0.48 & 0.26 & 0.53 \\
\hline $2-3 y$ & 2.5 & 52 & -0.09 & 0.40 & -0.21 & 0.02 \\
\hline $3-4 y$ & 3.5 & 49 & 0.04 & 0.34 & -0.06 & 0.14 \\
\hline $4-5 y$ & 4.5 & 48 & 0.31 & 0.31 & 0.22 & 0.40 \\
\hline $5-6 y$ & 5.5 & 48 & 0.34 & 0.27 & 0.26 & 0.42 \\
\hline $6-7 y$ & 6.5 & 48 & 0.02 & 0.52 & -0.13 & 0.17 \\
\hline
\end{tabular}

Bold figures indicate negative $\Delta$ SDS for weight. Italics indicate positive $\Delta$ SDS. Age and period are corrected age. $95 \%$ confidence intervals of the mean are given.

$\Delta \mathrm{SDS}=0$ indicates no change in SDS during the given period (no "channel growth" change).

During the "early" weight catch-up period (up to $40 \mathrm{wk}$ postmenstrual age), 23 of 52 infants reached their birth weight SDS and 27 of 52 infants achieved a positive weight SDS, although 10 infants were below -2 SDS in weight at this age. At 7 y of age, three children had a weight below -2 SDS and six were above 2 SDS. Mean SDS for the total group was then close to zero $(-0.02)$.

Three (8\%) of the 36 children (one child with GH substitution included) who were born in gestational weeks 27-28 were $<-2$ SDS in weight at 4 y of age, whereas $5(33 \%)$ of the 16 children (one child with GH substitution included) who were born in gestational weeks $24-26$ were $<-2$ SDS in weight at 4 y of age.

Length/height from 40 wk of gestation to $7 y$ of age. Length was not regularly measured (because of clinical practice) before the child was close to being discharged. At $40 \mathrm{wk}$ of GA, 13 of 52 infants were $<-2$ SDS in length. A length below -2 SDS was more commonly seen among the most immature infants, of whom 9 (56\%) of the 16 children who were born in gestational weeks 24-26, compared with 4 (11\%) of the 36 children who were born in gestational weeks 27-28, had a length below -2 SDS at $40 \mathrm{wk}$ (Tables 6 and 7). Mean length SDS for the total group was -1.08 . At 3 mo of corrected age, the corresponding mean value was -1.88 SDS. At $7 \mathrm{y}$ of corrected age, the total group mean SDS was close to normal (0.09). Multiple regression revealed that length SDS at $40 \mathrm{wk}$ postmenstrual age could be explained by $51 \%$ as a result of weight SDS at birth and GA and partly to sex $\left(R^{2}=0.506, p\right.$ $<0.001)$. The father's and/or mother's size had no influence. Corresponding values for weight SDS was $37 \%$ only. At 2 y of age, 10 of the children still remained below -2 SDS in height, and at $7 \mathrm{y}$ of age, two children were below -2 SDS, whereas three children were above 2 SDS. The three tall infants all were born at 28 wk of GA.

In agreement with the gain in weight, height recovery was more rapid among the children who were born in the later gestational weeks (27-28). For example, the upper 95\% confidence limit was below the lower 95\% confidence limit for infants who were born before 27 wk of gestation at 1, 2, and 3 mo of corrected age, as indicated by italics in Table 7. The time pattern is even better demonstrated in Table 8 , showing a linear catch-up growth in two separate periods. Although $\Delta$ SDS for weight was negative, $\Delta$ SDS for length was positive already at 3-6 mo and peaked at 6-12 mo of age. At 4-6 y of age, the second linear catch-up growth period occurred. Three (8\%) of the 36 children (one child with GH substitution included) who

Table 6. Length/height SDS for 52 infants born before 29 wk GA

\begin{tabular}{|c|c|c|c|c|c|}
\hline Corrected age & Lower 95\% & Mean & Upper 95\% & Min & Max \\
\hline 40 wk (52) & -1.35 & -1.08 & -0.81 & -3.34 & 0.96 \\
\hline $1 \mathrm{mo}(52)$ & -1.78 & -1.49 & -1.21 & -4.10 & 0.80 \\
\hline $2 \mathrm{mo}(52)$ & -2.06 & -1.75 & -1.45 & -4.69 & 0.77 \\
\hline 6 mo (52) & -2.09 & -1.70 & -1.30 & -5.66 & 1.33 \\
\hline 1 y (52) & -1.11 & -0.66 & -0.20 & -5.05 & 2.38 \\
\hline 2 y (52) & -1.00 & -0.57 & -0.14 & -4.37 & 2.48 \\
\hline 5 y (48) & -0.68 & -0.30 & 0.08 & -3.12 & 2.58 \\
\hline 6 y (48) & -0.15 & 0.22 & 0.60 & -1.88 & 3.26 \\
\hline 7 y (48) & -0.27 & 0.09 & 0.45 & -2.89 & 3.18 \\
\hline
\end{tabular}

Mean, upper, and lower $95 \%$ confidence interval of the mean and min, max are given. Mean and upper confidence limits of the mean below reference $=0$ indicated in bold. 
Table 7. Length/height SDS for infants born at $28 w k$ GA and comparison with lower GAs

\begin{tabular}{|c|c|c|c|c|c|c|}
\hline $\begin{array}{l}\text { Corrected } \\
\text { age }\end{array}$ & $\begin{array}{c}\text { Lower } 95 \% \\
28 \mathrm{wk}\end{array}$ & $\begin{array}{c}\text { Mean } \\
28 \mathrm{wk} \\
(n=25)\end{array}$ & $\begin{array}{c}\text { Upper } 95 \% \\
28 \text { wk }\end{array}$ & $\begin{array}{c}\text { Upper } 95 \% \\
<28 \text { wk } \\
(n=27-23)\end{array}$ & $\begin{array}{l}\text { Upper } 95 \% \\
<27 \text { wk } \\
(n=16-13)\end{array}$ & $\begin{array}{c}\text { Upper } 95 \% \\
<26 \text { wk } \\
(n=9-7)\end{array}$ \\
\hline $40 \mathrm{wk}$ & -1.07 & -0.73 & -0.38 & -1.03 & -1.07 & -0.90 \\
\hline $2 \mathrm{mo}$ & -1.73 & -1.34 & -0.97 & -1.69 & -1.75 & -1.44 \\
\hline $3 \mathrm{mo}$ & -1.85 & -1.45 & -1.05 & -1.80 & -1.86 & -1.52 \\
\hline $6 \mathrm{mo}$ & -1.66 & -1.21 & -0.75 & -1.56 & -1.65 & -1.27 \\
\hline $3 y$ & -0.64 & -0.14 & 0.34 & -0.38 & -0.08 & 0.52 \\
\hline $4 y$ & -0.76 & -0.29 & 0.19 & -0.54 & -0.37 & 0.13 \\
\hline $5 y$ & -0.46 & 0.06 & 0.59 & -0.17 & -0.03 & 0.23 \\
\hline $6 y$ & 0.00 & 0.54 & 1.09 & 0.37 & 0.49 & 0.64 \\
\hline $7 \mathrm{y}$ & -0.25 & 0.28 & 0.80 & 0.40 & 0.66 & 0.93 \\
\hline
\end{tabular}

Mean and upper confidence limits of the mean below reference $=0$ are indicated in bold. Separate $95 \%$ confidence intervals of the means (comparison with 28 weeks of gestation) are indicated by italics. Decreasing number $(n)$ as a result of excluded GH-treated children.

Table 8. Mean $\triangle S D S$ for height/length (individual changes) in all children for each time period

\begin{tabular}{|c|c|c|c|c|c|c|}
\hline Period & $\begin{array}{l}\text { Mean age } \\
\text { (y) }\end{array}$ & $n$ & $\begin{array}{c}\text { Mean } \Delta \text { SDS } \\
\text { height }\end{array}$ & SD & $\begin{array}{c}\text { Lower } \\
95 \%\end{array}$ & $\begin{array}{c}\text { Upper } \\
95 \%\end{array}$ \\
\hline $28-32$ wk & 0.042 & 52 & -0.41 & 0.19 & -0.47 & -0.36 \\
\hline $32-36 \mathrm{wk}$ & 0.13 & 52 & -0.26 & -0.18 & -0.31 & -0.21 \\
\hline $3-6 \mathrm{mo}$ & 0.38 & 52 & 0.18 & 0.38 & 0.07 & 0.29 \\
\hline $6-12 \mathrm{mo}$ & 0.75 & 52 & 1.04 & 0.47 & 0.91 & 1.17 \\
\hline $1-2 y$ & 1.5 & 52 & 0.09 & 0.58 & -0.08 & 0.25 \\
\hline $4-5 y$ & 4.5 & 48 & 0.34 & 0.47 & 0.20 & 0.48 \\
\hline $5-6 y$ & 5.5 & 48 & 0.52 & 0.31 & 0.44 & 0.61 \\
\hline $6-7 y$ & 6.5 & 48 & -0.13 & 0.90 & -0.40 & 0.13 \\
\hline
\end{tabular}

Bold figures indicate negative $\Delta$ SDS for weight. Italics indicative positive $\Delta$ SDS. Age and period are corrected age. $95 \%$ confidence intervals of the mean are given. $\Delta \mathrm{SDS}=0$ indicates no change in SDS during the given period (no "channel growth" change).

were born in gestational weeks $27-28$ were $<-2$ SDS in length at $4 \mathrm{y}$ of age, whereas $2(12 \%)$ of the 16 children (one child with GH substitution included) who were born in gestational weeks $24-26$ were $<-2$ SDS in length at $4 \mathrm{y}$ of age.

Multiple regression revealed that height SDS at $7 \mathrm{y}$ of corrected age could be explained by only the father's height $\left(R^{2}=33 \%, p<0.001\right)$, by the father's height and the infant's length SDS at $40 \mathrm{wk}$ postmenstrual age $\left(R^{2}=47 \%, p<\right.$ 0.001 ), and by the father's height together with the infant's length at $1 \mathrm{y}$ of corrected age $\left(R^{2}=63 \%, p<0.001\right)$. The mother's height, GA, sex, and weight SDS at birth had no further influence in the model.

Relationship between weight and height. At approximately $40 \mathrm{wk}$ postmenstrual age, the children had a higher weight SDS than length SDS, although this "chubbiness" at term was followed by a tendency toward leanness during childhood, normalizing at $7 \mathrm{y}$ of age (Tables 3 and 6).

Among the six children who were above 2 SDS in weight at $7 \mathrm{y}$ of age, two children were proportional according to weight for height with a difference of $<0.70$ SDS. The other four were obese, having a weight above 1.5 SDS in comparison with their height.

Correction for parental height. Standard correction performed for height in SDS, i.e. using midparental height SDS as the correction factor, produces little influence at the group level; large changes can be seen for some individuals. In all, 27 children were corrected to a more normal score (SDS closer to zero), and 17 became more deviant from zero after correction.

\section{DISCUSSION}

It takes the very preterm child up to $7 \mathrm{y}$ to catch up what is lost in weight and length during the first months of extrauterine life, as shown in the present study. However, nearly all children were close to normal in height and weight when they started school.

All infants had a marked drop in weight during the first weeks of life, and this was more pronounced in the most immature infants. Thereafter, a low weight gain was maintained for several weeks. Thus, at the time of discharge from the hospital, at an age corresponding to approximately 40 gestational wk, most infants had a lower weight than expected from their birth weight. In addition, they were shorter than could have been anticipated from their weight. Gill et al. (12) described a similar weight loss during the premature child's first weeks of life. It has also been demonstrated that children who were born between 24 and 29 wk of gestation had not achieved the median birth weight of reference fetuses with similar postmenstrual age. However, no follow-up after discharge from the hospital was presented (13). We showed that 
the children who were born very prematurely, as a group, remained growth retarded during the first years of life, with regard to both weight and length.

The study group is a cohort of children from the beginning of a new medical era. We think that the group is representative for its time period. Because of changing treatment regimens and epidemiology, growth patterns in very preterm infants who were born at a later time period need to be evaluated.

Our results are in agreement with other studies that suggest that children who are born very prematurely but at an appropriate weight for GA at birth have a growth spurt between 5 and $8 \mathrm{y}$ of age $(14,15)$. Approximately $90 \%$ of the children in the present study were within the normal range regarding weight and height at school age. It has been shown that children who are born preterm may experience catch-up growth even into their teens (16). However, these studies have not described any differences in the growth pattern and time for catch up as a result of GA, as in our study with a longer time lag in the more immature groups.

Earlier studies have shown that children who were born at term but small for gestational age showed catch-up growth as early as $12 \mathrm{wk}$ of postnatal age and that most of the total catch-up in height can be achieved by 2 mo of age (17). This growth pattern differs from that of infants who are born very prematurely, who take a much longer time to catch up, as demonstrated in our study. It is difficult to analyze growth in cohorts of infants categorized only by birth weight, without considering the GA. Depending on whether correction is made for GA, significant differences in interpretation of the growth pattern may be obtained. We found that most children reached their genetic potential based on the average height of the parents. These findings are in accordance with those of other groups, indicating that heredity is the major factor for growth up to at least the age of $8 \mathrm{y}$, in fact even more important than the prematurity itself $(14,16)$. Surprisingly, we found that only the height of the fathers had influence on the height obtained at $7 \mathrm{y}$ of age. The preterm infants in our study were heavy for their length from $40 \mathrm{wk}$ postconception until 3-4 mo of age. After this time, the children lost weight relative to height and became lean but normalized their body proportions before $7 \mathrm{y}$ of age. If only the child's weight were followed, then the catch-up growth at the time when the infants were ready to leave the hospital would probably be overestimated. It is also noteworthy that being born very prematurely will not protect from being overweight at $7 \mathrm{y}$, as four children had a weight SDS $>1.5$ above their height SDS.

The present study indicates the need to monitor linear growth in early life, especially as simple techniques are now available, allowing accurate estimation of the growth of the lower leg (18-21).

Growth from birth to maturity has been described as occurring in three additive phases: infancy, childhood, and puberty, i.e. the ICP-model (22). The infancy phase starts in midgestation and continues in a similar pattern during the first months after birth. Thereafter. it rapidly decreases and ends at approximately $4 \mathrm{y}$ of age. The onset of the second growth period, the childhood phase, normally occurs during the second half of the first postnatal year and is characterized by an increase in height gain. Our study clearly shows a distinct linear catch-up growth starting at the same time as the childhood component in the ICP model, if age corrected for GA is used. It may be speculated that preterm birth disturbs the normal regulation of the infancy growth period, resulting in a poor growth outcome during the first years, whereas the childhood growth period remains normal.

The last trimester is a critical developmental period. Studies on survivors of the Dutch famine have demonstrated that metabolic and cardiovascular outcome is dependent on the timing of malnutrition during fetal life $(23,24)$. Malnutrition in the last trimester resulted in decreased glucose tolerance later in life (25). As the preterm children in the present study were growth retarded during a postnatal period corresponding to the last trimester, it may be speculated that these children have the same risk for late sequelae as the children with intrauterine growth retardation. During the past decade, several studies have shown a relationship among low birth weight and postnatal growth, morbidity and mortality from cardiovascular disease, and metabolic changes such as increased insulin resistance and impaired glucose tolerance $(5,26-28)$. It has been shown that a low birth weight in combination with accelerated weight gain during childhood is associated with the highest risk ratio for cardiovascular disease later in life $(5,29)$. These studies did not specify children who were born very preterm, a group with a dramatic improvement in survival during the past decades. It may be speculated that the extrauterine growth retardation, as seen in the present group of children who were born very prematurely, is associated with the same risks as intrauterine growth retardation in full-term children, with regard to morbidity in adult life.

Acknowledgments. We are grateful to Ann-Helén Liljeström, Margareta Olsson, and Birgitta Svensson, GPGRC, and Petra Otterblad Olausson Medical birth registry for assistance with data collection.

\section{REFERENCES}

1. Arnold CC, Kramer MS, Hobbs CA, McLean FH, Usher RH 1991 Very low birthweight: a problematic cohort for epidemiological studies of very small or immature neonates. Am J Epidemiol 134:604-613

2. Kitchen WH, Doyle LW, Ford GW, Callanan C 1992 Very low birth weight and growth to age 8 years. I: weight and height. Am J Dis Child 146:40-45

3. Forrester TE, Wilks RJ, Bennett FI, Simeon D, Osmond C, Allen M, Chung AP, Scott P 1996 Fetal growth and cardiovascular risk factors in Jamaican schoolchildren. BMJ 312:156-160

4. Rich-Edwards JW, Stampfer MJ, Manson JE, Rosner B, Hankinson SE, Colditz GA, Hennekens CH, Willet WC 1997 Birth weight and risk of cardiovascular disease in a cohort of women followed up since 1976. BMJ 315:396-400

5. Eriksson JG, Forsén T, Tuomilehto J, Winter PD, Osmond C, Barker DJP 1999 Catch-up growth in childhood and death from coronary heart disease: longitudinal study. BMJ 318:427-431

6. Sörensen HT, Sabroe S, Olsen J, Rothman KJ, Gillman MW, Fischer P 1997 Birth weight and cognitive function in young adult life: historical cohort study. BMJ 315:401-403

7. Hård AL, Niklasson A, Svensson E, Hellström A 2000 Visual function in school-aged children born before 29 weeks of gestation: a population-based study. Dev Med Child Neurol 42:100-105

8. Marsal K, Persson P-H, Larsen T, Lilja H, Selbing A, Sultan B 1996 Intrauterine growth curves based on ultrasonically estimated foetal weights. Acta Paediatr 85:843-848

9. Niklasson A, Karlberg P 1999 New reference for Swedish infants size at birth. Horm Res 51(suppl 2):28

10. Albertsson Wikland KA, Luo ZC, Niklasson A, Karlberg J 2002 Swedish populationbased longitudinal reference values from birth to 18 years of age for height, weight and head circumference. Acta Paediatr 91:739-754 
11. Karlberg J, Albertsson-Wikland K 1995 Growth in full-term small-for-gestational age infants: from birth to final height. Pediatr Res 38:1-7

12. Gill A, Yu VY, Bajuk B, Astbury J 1986 Postnatal growth in infants born before 30 weeks' gestation. Arch Dis Child 61:549-553

13. Ehrencrantz RA, Younes N, Lemons JA, Fanaroff AA, Donovan EF, Wright LL, Katsikiotis V, Tyson JE, Oh W, Shankaran S, Bauer CR, Korones SB, Stoll BJ, Stevenson DK, Papile L 1999 Longitudinal growth of hospitalized very low birth weight infants. Pediatrics 104:280-289

14. Ross G, Lipper EG, Auld PA 1990 Growth achievement of very low birth weight premature children at school age. J Pediatr 117:307-309

15. Qvigstad E, Verloove-Vanhorick SP, Ens-Dokkum MH, Schreuder AM, Veen S, Brand R, Oostdijk W, Ruys JH 1993 Prediction of height achievement at five years of age in children born very preterm or with very low birth weight: continuation of catch-up growth after two years of age. Acta Paediatr 82:444-448

16. Hirata T, Bosque E 1998 When they grow up: the growth of extremely low birth weight $(>1000 \mathrm{gm})$ infants at adolescence. J Pediatr 132:1033-1035

17. Karlberg JP, Albertsson-Wikland K, Kwan EY, Lam BC, Low LC 1997 The timing of early postnatal catch-up growth in normal, full-term infants born short for gestational age. Horm Res 48:17-24

18. Michaelsen KM, Skow L, Badsberg JH, Jörgensen M 1991 Short-term measuremen of linear growth in preterm infants: validation of a hand-held knemometer. Pediat Res 30:464-468

19. Gibson AT, Pearse RG, Wales JK 1993 Knemometry and the assessment of growth in premature babies. Arch Dis Child 69:498-504

20. Hermanussen M, Seele K 1997 Mini-knemometry: an accurate technique for lower leg length measurements in early childhood. Ann Hum Biol 24:307-313
21. Engström E, Wållgren K, Hellström A, Niklasson A 2003 Knee-heel length measurements in preterm infants: evaluation of a simple electronically equipped instrument. Acta Pediatr 92:211-215

22. Karlberg J 1987 Modeling of human growth. Thesis. Göteborg University, Sweden

23. Roseboom TJ, van Der Meulen JH, Osmond C, Barker DJ, Ravelli AC, Bleker OP 2000 Plasma lipid profiles in adults after prenatal exposure to the dutch famine. Am J Clin Nutr 72:1101-1106

24. Roseboom TJ, van Der Meulen JH, Osmond C, Barker DJ, Ravelli AC, SchroederTanka JM, van Montfrans GA, Michels RP, Bleker OP 2000 Coronary heart disease after prenatal exposure to the dutch famine, 1944-45. Heart 84:595-598

25. Ravelli AC, van Der Meulen JH, Michels RP, Osmond C, Barker DJ, Hales CN, Bleker OP 1998 Glucose tolerance in adults after prenatal exposure to famine. Lancet 351:173-177

26. Barker DJP, Osmond C, Golding J, Kuh D, Wadsworth ME 1989 Growth in utero, blood pressure in childhood and adult life, and mortality from cardiovascular disease. BMJ 298:564-567

27. Phipps K, Barker DJ, Hales CN, Fall CH, Osmond C, Clark PM 1993 Fetal growth and impaired glucose tolerance in men and women. Diabetologia 36:225-228

28. Barker DJP 1995 Fetal origins of coronary heart disease. BMJ 311:171-174

29. Lucas A, Fewtrell MS, Cole TJ 1999 Fetal origins of adult disease - the hypothesis revisited. BMJ 319:245-249

30. Papile LA, Burstein J, Burstein R, Koffler H 1978 Incidence and evolution of subependymal and intraventricular hemorrhage: a study of infants with birth weights less than 1,500 gm. J Pediatr 92:529-534

31. The Committee for the Classification of Retinopathy of Prematurity 1984 An international classification of retinopathy of prematurity. Arch Ophthalmol 102:1130-1134 